\title{
UTILIZAÇÃO DE MODELO DE REFERÊNCIA NO DESENVOLVIMENTO DE PRODUTO: ESTUDO DE CASO DE UM DEBULHADOR DE MILHO
}

Mauricio Guilherme Pereira de Melo (mauricioguax@hotmail.com) - Centro Universitário da Fundação Educacional Guaxupé, Unifeg.

Rodrigo Furlan de Assis (furlan@puccaldas.br) - Pontifícia Universidade Católica de Minas Gerais campus Poços de Caldas, PUC.

Cintia Blaskovsky Portilho Gomes (cintiablasky@gmail.com) - Centro Universitário da Fundação Educacional Guaxupé, Unifeg.

\section{RESUMO}

$O$ objetivo da presente pesquisa é propor a utilização do modelo de referência para o desenvolvimento de produtos (PDP), proposto por Rozenfeld et al. (2006), em uma empresa na qual não se utiliza nenhuma metodologia específica para o desenvolvimento de um debulhador de milho. Sendo estruturada na forma de um estudo de caso, em uma empresa especializada no ramo metal-mecânica voltada para a transformação de chapas metálicas em componentes para máquinas agrícolas por meio de processos de conformação mecânica. Após estudos iniciais, constataram-se ganhos significativos no entendimento do projeto, promovendo melhorias com cada etapa finalizada e um melhor sistema de gestão, proporcionando ganho em tempo. Assim, foi possível verificar que a sistematização de processos do modelo de referência amplia a capacidade da empresa em gerenciar os recursos disponíveis para o produto em questão, $e$ a partir disso o processo de desenvolvimento foi aprimorado na empresa pesquisada.

Palavras-chave: Processo de desenvolvimento de produtos; modelos de referência; gerenciamento de recursos.

Área: Gestão do processo e Desenvolvimento de Produtos

\section{INTRODUÇÃO}

Para Mehandjiev et al. (2009), as modificações econômicas contemporâneas impõem a concepção de novas formas de se pensar sobre a organização baseado em mecanismos resilientes. Com isso, é imperativo que as empresas sejam proativas a este cenário de alterações comerciais para sustentar a sua competitividade e, consequentemente, a sua sobrevivência.

Com base nisso, a mudança das organizações para configurações flexíveis e dinâmicas, evidencia que as abordagens tradicionais de gestão enfrentam dificuldades para cobrir o 
amplo escopo exigido e, como resultado, podem não ser mais eficiente (LOSS; CRAVE, 2011).

Para Cheng e Filho (2007), o diferencial competitivo de uma organização está relacionada à introdução de novos produtos e serviços no mercado que satisfaçam as exigências dos consumidores, sendo este aspecto um ponto fundamental para a longevidade das organizações. Nesse sentido, Kotler e Armstrong (2007) afirmam que em decorrências às mudanças de mercado, as empresas, cada vez mais, precisam desenvolver um fluxo no processo de desenvolvimento de novos produtos. Para tanto, Barczak et al. (2009) propõe que a capacidade de ampliar a vantagem competitiva deve estar centrada na inovação por meio do processo de desenvolvimento de produto (PDP), isso decorre do fato de ser um dos aspectos organizacionais mais complexos para replicar.

Sendo assim, o PDP é definido como um conjunto de atividades por meio das quais se utilizam dados referentes às necessidades do mercado, bem como possibilidades e restrições tecnológicas, levando em consideração estratégias competitivas da empresa, para gerar informações de valor para a produção comercial de projeto de um produto e de seu processo de produção (CLARK; FUJIMOTO, 1991; ROZENFELD et al., 2006; AMIGO, 2013).

Segundo Faria et al. (2008), é possível identificar na literatura diversas metodologias para o PDP. Contudo, segundo Rieg e Alves Filho (2003), a maioria das pequenas e médias empresas não possui estruturação para o PDP, isso ocorre porque tais empresas, em geral, não possuem condições para manter um PDP como unidade organizacional, desenvolvendo mecanismos alternativos para assegurar um adequado ritmo de inovação e lançamento de novos produtos.

Segundo Costa e De Lima Leandro (2016), as micro e pequenas empresas possuem um papel relevante na economia nacional, contribuindo com 27\% do PIB brasileiro, em valores absolutos isso significa R\$ 599 bilhões (SEBRAE, 2015). Todavia, dadas as dificuldades gerenciais enfrentadas pelos gestores de micro e pequenos negócios, 58\% das empresas de pequeno porte encerraram as suas atividades antes de completar cincos anos.

Nesse contexto, o objetivo da presente pesquisa é adaptar o modelo de referência para o PDP proposto por Rozenfeld et al. (2006), em uma pequena empresa do setor metal-mecânico. O trabalho justifica-se pela importância de identificar oportunidades de melhoria no PDP, principalmente para micro e pequenas empresas, na busca por melhorias e para o estabelecimento de vantagem competitiva no mercado.

Para tal, a pesquisa é classificada como um estudo de caso, envolvendo um produto projetado e fabricado em uma empresa de caldeiraria situada no município de Guaxupé, Estado de Minas Gerais.

O presente artigo está dividido em seis seções, incluindo a introdução. Na segunda seção é desenvolvida a fundamentação teórica, sendo que a terceira seção apresenta a metodologia de pesquisa. Na sequência, é exposto e discutido o modelo proposto (seção 4) e os resultados discutidos (seção 5). Por fim, são desenvolvidas as análises conclusivas na seção 6.

\section{MODELO DE REFERÊNCIA ADOTADO}

A modelagem não é exclusividade apenas de processos fabris, mas também é de grande valor em processos de desenvolvimento de produtos (SMITH; MORROW, 1999; ENGWALL et al., 2005).

Segundo Rozenfeld et al. (2006), o desenvolvimento de produtos é um processo de negócio cada vez mais crítico devido à internacionalização dos mercados, o aumento da diversidade de 
produtos e a redução dos seus ciclos de vida. Sendo assim novos produtos buscam atender segmentos específicos de mercado, incorporando novas tecnologias e se adequando a novos padrões e restrições legais.

O modelo de referência de Rozenfeld et al. (2006) é um modelo genérico compostos por nove fases, sendo elas divididas em três macro fases: pré-desenvolvimento, desenvolvimento e pósdesenvolvimento, conforme Figura 1.

Figura 1. Etapas do processo de desenvolvimento de produtos

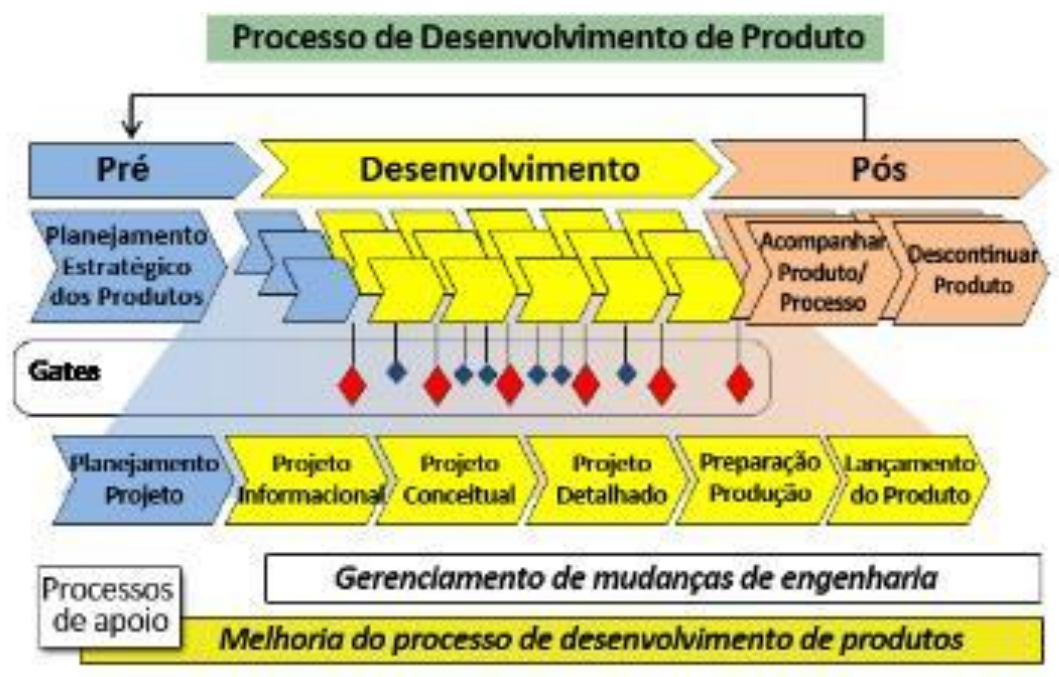

Fonte: Rozenfeld et. al. (2006)

A proposta de Rozenfeld et al. (2006) destacam a relevância das atividades de desenvolvimento e pós-desenvolvimento para a estruturação do PDP. A partir disso, os autores indicam que o pré-desenvolvimento é composto por duas fases: planejamento estratégico de produtos, onde são analisadas as informações estratégias, que contém a descrição do portfólio de produtos; e planejamento do projeto, onde é determinado o escopo e organização macro do projeto do produto selecionado no portfólio. Dessa forma, o desenvolvimento é composto por cinco fases:

a) Projeto informacional: onde se elaboram as especificações-meta do produto;

b) Projeto conceitual: onde é elaborado o conceito do produto e a definição da sua arquitetura;

c) Projeto detalhado: onde se realizam todos os cálculos e desenhos detalhados para a produção, protótipos do produto, e planos de lançamento, vendas e apoio ao produto no mercado;

d) Preparação da produção: onde são realizadas as especificações de máquinas e ferramentas e dos métodos de produção, e é gerada toda a documentação necessária para produzir o produto com qualidade; e

e) Lançamento do Produto: onde o produto é lançado e o time de desenvolvimento desfeito.

Já o pós-desenvolvimento é composto pelas fases de acompanhamento do produto e processo e descontinuação do produto no mercado. Realiza o acompanhamento sistemático e produz a documentação correspondente às melhorias de um produto ao longo da sua vida útil. Inclui a 
retirada sistemática do produto do mercado e a avaliação de todo o seu ciclo de vida, para que sirva de referência para desenvolvimentos futuros (ROZENFELD et al., 2006).

Ao término de cada fase é realizada uma verificação do plano para a próxima, analisando em cada etapa a viabilidade econômico-financeira para que o projeto possa ter continuidade. $\mathrm{O}$ gate é uma etapa em que se aprova a fase terminada, documentando as decisões tomadas e lições aprendidas. Existem dois processos de apoio que executados paralelamente às fases, o processo de gerenciamento de mudanças de engenharia e o processo de melhoria do PDP (ROZENFELD et al., 2006).

Segundo Campos e Ribeiro (2011) o modelo de referência de Rozenfeld et al. (2006) ressaltam a necessidade de integração entre os stakeholders no desenvolvimento de produtos, com a proposta de maximizar a utilização dos recursos e obter agilidade no processo. Além disso, por meio do modelo é possível condicionar mecanismos que possibilitem o monitoramento da viabilidade econômico-financeira do projeto.

Além disso, para Jugend e Silva (2010) o modelo de PDP proposto por Rozenfeld et al. (2006) é reconhecido como um trabalho que associa as boas práticas presentes em estudos clássicos sobre a gestão de desenvolvimento de novos produtos e ainda apresenta grande nível de detalhamento para as suas atividades, por essa característica tal modelo foi selecionado para a aplicação da presente pesquisa.

\section{MÉTODO DE PESQUISA}

\subsection{Contexto}

O método de pesquisa utilizado no presente artigo foi um estudo de caso. Segundo Yin (2010), os estudos de caso proporcionam a compreensão de como realmente acontecem os processos de trabalho, possibilitando observar o que está sendo estudado com os melhores detalhes.

Deste modo, foi feito um estudo de caso sobre a aplicação do modelo de referência do PDP desenvolvido por Rozenfeld et al. (2006), onde foram analisadas todas as etapas de projeto, levando em consideração que não há um modelo de processo específico para a empresa em estudo. Cabe destacar que para a aplicação do referido modelo de PDP foram feitas adaptações do modelo à realidade da empresa.

\subsection{Desenvolvimento do estudo}

O estudo foi realizado em uma empresa de pequeno porte do ramo de caldeiraria, situada no município de Guaxupé, do Estado de Minas Gerais. A empresa atua no ramo voltado para a transformação de chapas metálicas em componentes, para máquinas agrícolas, locomotivas, entre outros segmentos, por meio de processos de conformação mecânica. Os processos que não são especialidades da empresa, tais como pintura e instalação elétrica, são obtidos por meio de parceiros e processados na empresa. Por se tratar de uma empresa de pequeno porte, o investimento na área de desenvolvimento de produto é pequeno, tendo as adaptações e melhorias de soluções já comercializadas, como principal fonte de informações para melhorias futuras no desenvolvimento de produtos.

Nesse sentido, foi utilizado o modelo de referência de Rozenfeld et al. (2006) com a proposta de formalizar o PDP na empresa pesquisada. Este modelo apresenta granularidade de tarefas específicas em cada uma das fases a serem seguidas, fazendo que seja mais prática a inserção do modelo no produto estudado. 


\section{APLICAÇÃO DO MODELO DE REFERÊNCIA}

Baseada na metodologia do PDP de Rozenfeld et al. (2006), a partir da macro fase de prédesenvolvimento foi elaborado o planejamento estratégico com os stakeholders por meio de visitas in loco para que fosse possível obter inovações ligadas ao produto em estudo. Por meio das informações coletadas notou-se que por se tratar de um debulhador de milho, o mesmo apresenta pré-requisitos que possibilitam condições de desenvolver novas ferramentas que pudessem debulhar outros tipos de grãos, podendo ser uma máquina multifuncional ou específica para tal.

Posterior a essa etapa, foi iniciado o planejamento do projeto por meio de uma equipe multidisciplinar de colaboradores da empresa pesquisada. Dessa forma, com a experiência da equipe foram definidos os recursos necessários embasado numa visão sistémica das atividades, conforme apresentado na Tabela 1.

Tabela 1. Análise de atividades

\begin{tabular}{|c|c|c|c|}
\hline Atividades & Entradas & Saídas & Recursos \\
\hline $\begin{array}{l}\text { Definir interessados } \\
\text { do projeto }\end{array}$ & $\begin{array}{l}\text { Proposta do produto, } \\
\text { Perfil do pessoal e Restrições } \\
\text { organizacionais. }\end{array}$ & $\begin{array}{c}\text { Planejamento } \\
\text { organizacional do projeto. } \\
\text { Montagem e } \\
\text { desenvolvimento. }\end{array}$ & $\begin{array}{c}\text { Melhores práticas } \\
\text { de gerenciamento } \\
\text { de RH }\end{array}$ \\
\hline $\begin{array}{l}\text { Definir escopo do } \\
\text { produto }\end{array}$ & $\begin{array}{l}\text { Portfólio de produtos } \\
\text { Escopo de produtos similares }\end{array}$ & Escopo do produto & $\begin{array}{c}\text { Técnicas de } \\
\text { discussão em } \\
\text { grupo }\end{array}$ \\
\hline $\begin{array}{l}\text { Adaptar o modelo de } \\
\text { referência }\end{array}$ & $\begin{array}{l}\text { Modelo de referência específico } \\
\text { do PDP da empresa }\end{array}$ & $\begin{array}{c}\text { Modelo de referência } \\
\text { específico adaptado para o } \\
\text { projeto }\end{array}$ & $\begin{array}{l}\text { Avaliação do grau } \\
\text { de complexidade e } \\
\text { inovação do } \\
\text { produto }\end{array}$ \\
\hline $\begin{array}{l}\text { Definir atividades e } \\
\text { sequência }\end{array}$ & Modelo de referência adaptado & $\begin{array}{l}\text { Listagem das atividades e } \\
\text { seus relacionamentos }\end{array}$ & $\begin{array}{c}\text { Técnicas de } \\
\text { discussão em } \\
\text { grupo }\end{array}$ \\
\hline $\begin{array}{c}\text { Analisar a } \\
\text { viabilidade } \\
\text { econômica do projeto }\end{array}$ & $\begin{array}{l}\text { Desenvolvimento dos orçamentos } \\
\text { para a execução do projeto }\end{array}$ & $\begin{array}{l}\text { Definição dos principais } \\
\text { indicadores financeiros do } \\
\text { projeto relacionados com o } \\
\text { produto final }\end{array}$ & Análise financeira \\
\hline $\begin{array}{l}\text { Definir indicadores } \\
\text { de desempenho }\end{array}$ & $\begin{array}{l}\text { Modelo de referência adaptado } \\
\text { para o projeto }\end{array}$ & $\begin{array}{l}\text { Formulação de indicadores } \\
\text { do desempenho para as } \\
\text { fases e atividades do DP }\end{array}$ & \\
\hline $\begin{array}{l}\text { Definir plano de } \\
\text { comunicação }\end{array}$ & $\begin{array}{c}\text { Tipos e formatos das informações } \\
\text { demandadas }\end{array}$ & $\begin{array}{c}\text { Plano de gerenciamento } \\
\text { das comunicações para o } \\
\text { projeto }\end{array}$ & $\begin{array}{c}\text { Rede } \\
\text { compartilhada }\end{array}$ \\
\hline
\end{tabular}

Fonte: Elaborado pelos autores.

$\mathrm{Na}$ macro fase de desenvolvimento do produto foi definido o projeto informacional que incorporou algumas premissas, tais como:

a) Agricultura familiar: Que gera toda sua renda com seus próprios familiares, sem a contratação de terceiros para a prestação de serviço.

b) Custo benefício: Proporcionando ao consumidor uma grande facilidade em debulhar o grão quando lhe for conveniente e conseguindo conciliar com outras atividades.

c) Funcionalidade: Sendo capaz de debulhar outros grãos e de se locomover para melhor 
ajuste do operador.

d) Investimento baixo: Permitindo que seja de fácil aquisição, por meio de um produto pequeno e de baixo consumo elétrico.

Visando atingir um público específico e proporcionar um alto índice de satisfação. Em seguida, o projeto conceitual levantou dificuldades que poderiam atingir o desenvolvimento, tanto no design quanto na funcionalidade que estão interligados, pois nem sempre que se tem um produto com aparência desejada, indica que tem uma capacidade produtiva adequada, conforme apresentado na Tabela 2.

Tabela 2. Dificuldades no projeto conceitual

\begin{tabular}{|c|c|}
\hline Dificuldade & Impacto \\
\hline $\begin{array}{c}\text { Análise de sistemas, subsistemas e } \\
\text { componentes (SSC) }\end{array}$ & $\begin{array}{c}\text { O funcionamento não atendendo as especificações do produto, } \\
\text { podendo haver avarias durante a sua utilização. }\end{array}$ \\
\hline Ergonomia & $\begin{array}{c}\text { Projeto com adequações às normas de segurança NR-12 para } \\
\text { máquinas e equipamentos (BRASIL, 2017) }\end{array}$ \\
\hline Definir fornecedores e parceiros & Interfere no lead time e na qualidade. \\
\hline
\end{tabular}

Fonte: Elaborado pelos autores.

Adiante foram formuladas as especificações do produto. Para essa etapa foi utilizado o software Solid Works, pois o mesmo permitiu avaliar seus componentes virtualmente, por meio de simulações e testes de movimento, proporcionando um alto índice de confiabilidade e reduzindo custos em testes de campo. Desse modo, o produto foi planejado para que obtivesse o melhor rendimento possível, dentro do que foi pré-estabelecido nas etapas anteriores.

A finalidade do mesmo visa separar os grãos de milho de sua espiga, palhada e selecioná-los entre os demais que não se aproveita para nenhum fim. O processo que a espiga de milho percorre na máquina até que se obtenha o grão limpo de impurezas e assim selecionado, é basicamente composto por quatro etapas:

- Depositar a espiga de milho na entrada da máquina;

- Esmigalhar a espiga, fazendo com que o grão se desprenda;

- Peneirar, separando o grão da palhada;

- Selecionar os grãos de má qualidade dos demais por meio de sucção de ar que os retira pela sua densidade menor.

Desse modo, todos os sistemas, subsistemas e componentes foram projetados visando o desempenho e qualidade do produto, proporcionando um ciclo de vida maior. Em seguida, com o intuito de agregar maior confiabilidade ao processo, todas as peças contam com uma folha de instrução de processo conforme ilustrado na Figura 3, onde são especificadas as dimensões, ângulos e demais cotas críticas que podem causar impactos em sua montagem posteriormente.

Tais folhas de instrução visam garantir que o colaborador tenha acesso a todas as suas características e especificações evitando possíveis falhas. Assim são classificadas em subsistemas como depósito, processamento e seleção do grão. 
Figura 3. Folha de instrução de processo

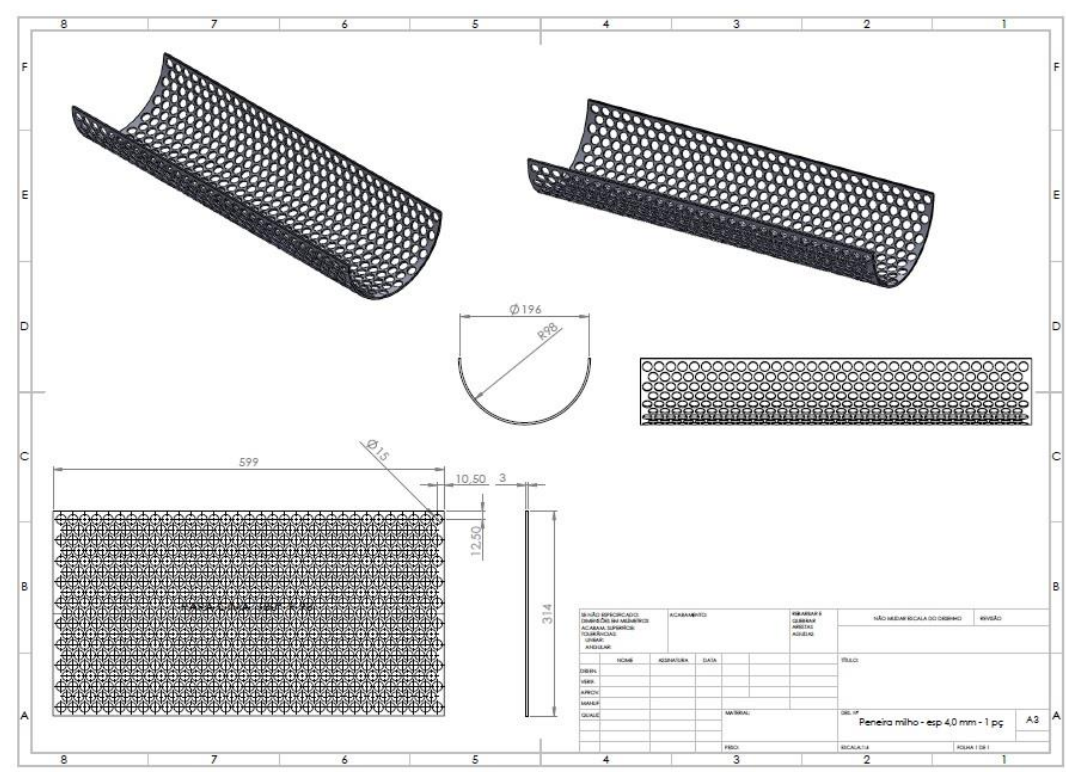

Fonte: Elaborado pelos autores.

Na fase de preparação da produção do produto observou-se que por se tratar de uma empresa inserida no ramo metalúrgico, obteve uma acessibilidade maior em definir sua cadeia de suprimentos em seu processo de produção, pois a empresa dispõe de maquinários para o processamento necessário, tais como: Corte laser; Corte plasma; Oxicorte; Dobra CNC; Dobra convencional; Solda; Usinagem; Pintura.

O lançamento do produto dispôs de um manual de utilização contendo o termo de garantia com duração de um ano, informações de instalação e como contatar a assistência técnica que atende nas primeiras 50 horas de trabalho e posteriormente a cada 200 horas.

Assim sendo desenvolvidas pela empresa adequando as atividades já existentes de forma eficaz. Para propaganda criou-se um panfleto informando as especificações, características do produto (Capacidade produção; Dimensões; RPM; Motorização; Peso), contato e imagem em diferentes vistas para que chame a atenção do consumidor, conforme apresentado na Figura 4.

Figura 4. Panfleto de vendas
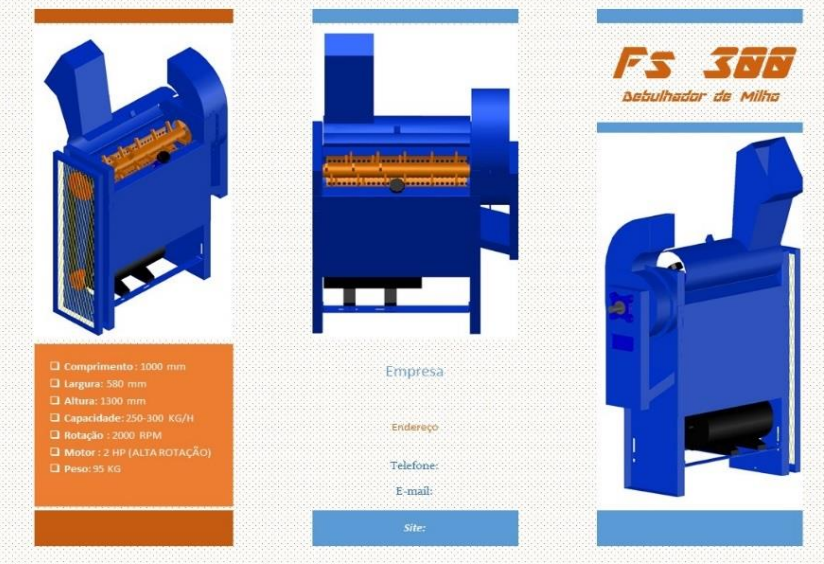

Fonte: Elaborado pelos autores. 
$\mathrm{Na}$ macro fase de pós-desenvolvimento, o acompanhamento do produto e do processo desenvolveu um controle da quantidade de vendas embasado em um lote mínimo que viabilize a produção do mesmo em um período mensal para que fosse possível analisar o índice de aceitação quanto aos clientes. Como mostra a Tabela 3.

Tabela 3. Aceitação do produto

\begin{tabular}{|c|c|c|c|}
\hline Grau de aceitação & Ruim & Médio & Bom \\
\hline Dendas 0 a 2 & $X$ & & \\
\hline De 3 a 5 & & $X$ & \\
\hline Acima de 6 & & & $X$ \\
\hline
\end{tabular}

Fonte: Elaborado pelos autores.

$\mathrm{O}$ produto em estudo tem seu grau de complexidade baixo, mas como todos os produtos podem ser aperfeiçoados, independentemente do seu grau de complexidade, as mudanças podem ser simples ou até a com um grau de complexidade elevado.

Em se tratando de informações do PDP na empresa pesquisada, é possível o modelo de referência seja adotado pela empresa, pois se tratando disso a empresa possui uma rede compartilhada informatizada, possibilitando o acesso aos desenhos técnicos e especificações, proporcionando um centro de informações. Deste modo, permite que o gerenciamento da engenharia do produto tenha maior eficiência.

\section{ANÁLISE DOS RESULTADOS}

Após a inserção do modelo no processo de desenvolvimento do produto estudado, notou-se que as contribuições permitiram um melhor acompanhamento do projeto por meio de reuniões semanais programadas, cronogramas das atividades, documentação e diversas formas de arranjo de recursos, custos, suprimentos, entre outros, geradas a partir de filtragens de informações em planilhas eletrônicas, sendo capaz de estabelecer uma metodologia de trabalho, criando um ambiente favorável a melhorias e quaisquer reformulações.

Além disso, constatou-se que houve uma uniformidade entre as áreas abrangentes do processo, evoluindo a comunicação e interação entre os envolvidos; maior eficiência na busca de recursos; melhor sequenciamento de tarefas; identificação de habilidades necessárias e adaptação de pessoal ao processo.

Ainda convém ressaltar que a representação do modelo de referência viabiliza uma atualização rápida e fácil do conteúdo por meio de planilhas da árvore do produto, interligadas ao estoque e custo do produto, que se dispõe de dados pré-estabelecidos associados a fórmulas financeiras.

A partir disso, tais planilhas, ainda permitem realizar orçamentos, check-list de necessidade de estoque, que possibilitam uma melhor gestão do processo de tomada de decisão. Cabe evidenciar que diversos processos foram desenvolvidos simultaneamente, pois a visibilidade da estrutura do modelo de referência acelerou o processo de análise de riscos.

Notou-se o ganho de tempo nas atividades foi significativo em relação a um processo em que não se segue nenhum tipo de modelo, pois a forma em que o modelo sequencia as atividades mostra quais etapas estão vinculadas e quais são independentes permitindo uma execução simultânea das mesmas e contribuindo para que se obtenha um projeto executável. 


\section{CONSIDERAÇÕES FINAIS}

O estudo realizado mostra a relevância de utilizar o modelo de referência no desenvolvimento de um produto, pois a forma em que os dados são coletados e analisados possibilita que sempre haja melhorias no processo e possa atingir níveis consideráveis de atendimento ao cliente.

O objetivo geral desse trabalho foi atingido, pois, por meio do levantamento do estado anterior do desenvolvimento do produto e da identificação das áreas deficientes com oportunidades de melhorias, foi elaborado o PDP para o caso em estudo. Além disso, orientase que a empresa formalize seus processos, para que favoreça a sua estrutura e documentação, utilizando indicadores de desempenho, árvore do produto, e para que possibilite futuras certificações.

Conclui-se que essa metodologia para o desenvolvimento de produto mostrou-se muito eficiente, mesmo que o produto estudado seja de baixa complexidade e limitações por parte da empresa, foi possível captar a relevância das várias etapas propostas no PDP, como o desenvolvimento de ideias que atendam uma necessidade específica, uma análise de mercado, os projetos conceituais e detalhados e a resolução do processo de produção.

Além disso, o trabalho também permitiu observar quais são características que um gestor de desenvolvimento de produtos necessita para administrar todo esse processo.

\section{REFERÊNCIAS}

AMIGO, C. R. Modelos de referência para o processo de desenvolvimento de produtos: novas possibilidade de representação. USP, São Carlos, p. 258, 2013.

BARCZAK, G.; GRIFFIN, A.; KAHN, K. B. Perspective: trends and drivers of success in NPD Practices: Results of the 2003 PDMA Best Practices Study. Journal of Product Innovation Management, v. 26, n. 1, p. 3-23, 2009.

BRASIL. Ministério do Trabalho e Emprego. NR- 12 - Segurança no trabalho em máquinas e equipamentos. Manuais de Legislação. Edição. São Paulo: Atlas, 2017.

CAMPOS, S. U.; RIBEIRO, J. L. D. Um modelo de referência para o processo de desenvolvimento de produtos de empresas do setor moageiro de trigo. Produção. Porto Alegre. Vol. 21, n. 3 (jul./set. 2011), p. 379-391., 2011.

CHENG, L. C.; MELO FILHO, L. D. R. QFD Desdobramento da função da qualidade na gestão de desenvolvimento de produtos. São Paulo: Blucher, 2007.

CLARK, K. B.; FUJIMOTO, T. Product development performance: strategy, organization and management in the word auto industry. Boston-Massachusetts: Harvard Business School Press, 1991.

COSTA, A. P. N.; DE LIMA LEANDRO, L. A. O Atual Cenário Das Micro E Pequenas Empresas No Brasil. In: Simpósio de Excelência em Gestão e Tecnologia, XIII. Anais... Rio de Janeiro, RJ: ABEPRO, 2016.

ENGWALL, M.; KLING, R.; WERR, A. Models in action: how management models are interpreted in new product development. R and D Management, v. 35, n. 4, p. 427-439, 2005. 
FARIA, A. F.; PINTO, A. C. A.; RIBEIRO, M. N.; CARDOSO, T. S.; RIBEIRO, J. P. C. Processo de desenvolvimento de novos produtos: uma experiência didática. In: ENCONTRO NACIONAL DE ENGENHARIA DE PRODUÇÃO, XXVIII. Anais... Rio de Janeiro, RJ: ABEPRO, 2008.

JUGEND, D.; SILVA, S. L. Práticas de gestão que influenciam o sucesso de novos produtos em empresas de base tecnológica. Revista Produção, v. 20, n. 3, p. 335-346, 2010.

KOTLER, P.; ARMSTRONG, G. Princípios de marketing. 12 ed. São Paulo: Prentice-Hall, 2007.

LOSS, L.; CRAVE, S. Agile Business Models: an approach to support collaborative networks. Production Planning \& Control, v. 22, n. 5-6, p. 571-580, 2011.

MEHANDJIEV, N.; GREFEN, P.; KOUVAS, G.; WEICHHART, G.; ESHUIS, R. Dynamic business network process management in instant virtual enterprises. Computers in Industry, v. 60, n. 2, p. 86-103, 2009.

RIEG, D. L.; ALVES FILHO, A. G. Atividades internas de P\&D e fontes externas de tecnologia: o caso das empresas do setor médico hospitalar de São Carlos. In: XXIII Encontro Nacional de Engenharia de Produção, 2003, Ouro Preto. Anais do ENEGEP 2003. Rio de Janeiro: ABEPRO, 2003.

ROZENFELD, H.; FORCELLINI, F. A.; AMARAL, D. C. Gestão de Desenvolvimento de Produtos. 1 ed. São Paulo: Saraiva Editora, 2006.

SEBRAE. Micro e pequenas empresas geram 27\% do PIB do Brasil. 2015a. Disponível em: $<$ http://www.sebrae.com.br/sites/PortalSebrae/ufs/mt/noticias/Micro-e-pequenas-empresasgeram-27\%25-do-PIBdo-Brasil> Acesso em: 23, abr., 2017.

SMITH, R. P.; MORROW, J. A. Product development process modeling. Design Studies, v. 20, n. 3, p. 237-261, 1999.

YIN, R. K. Estudo de caso: planejamento e método. Porto Alegre: Bookman, 2010. 